\title{
Balance of nanostructure and bimetallic interactions in Pt model fuel cell catalysts: An in situ XAS and DFT study
}

Daniel Friebel, Venkatasubramanian Viswanathan, Daniel James Miller, Toyli Anniyev, Hirohito Ogasawara, Ask Hjorth Larsen, Christopher P. O'Grady, Jens K. Norskov, and Anders Nilsson J. Am. Chem. Soc., Just Accepted Manuscript • DOI: 10.1021/ja3003765 • Publication Date (Web): 22 May 2012

Downloaded from http://pubs.acs.org on May 30, 2012

\section{Just Accepted}

"Just Accepted" manuscripts have been peer-reviewed and accepted for publication. They are posted online prior to technical editing, formatting for publication and author proofing. The American Chemical Society provides "Just Accepted" as a free service to the research community to expedite the dissemination of scientific material as soon as possible after acceptance. "Just Accepted" manuscripts appear in full in PDF format accompanied by an HTML abstract. "Just Accepted" manuscripts have been fully peer reviewed, but should not be considered the official version of record. They are accessible to all readers and citable by the Digital Object Identifier (DOI®). "Just Accepted" is an optional service offered to authors. Therefore, the "Just Accepted" Web site may not include all articles that will be published in the journal. After a manuscript is technically edited and formatted, it will be removed from the "Just Accepted" Web site and published as an ASAP article. Note that technical editing may introduce minor changes to the manuscript text and/or graphics which could affect content, and all legal disclaimers and ethical guidelines that apply to the journal pertain. ACS cannot be held responsible for errors or consequences arising from the use of information contained in these "Just Accepted" manuscripts. 


\section{INTRODUCTION}

Bimetallic catalyst materials are of great interest due to their wide variability of the electronic structure that allows for "tuning" of the catalyst affinity to various reaction intermediates. Such a tuning is needed in particular for the oxygen reduction reaction (ORR) in fuel cells, where a significant reduction of Pt loading is essential for economic viability. For transition metal catalysts, the effect of bimetallic interactions can be rationalized with a shift of the $d$-band center ${ }^{1-3}$ that is induced by the lattice expansion or compression (strain effect) ${ }^{4}$ and by orbital interactions between the two different metals (ligand effect). ${ }^{4-6}$ The $d$-band shift corresponds to a change of the $d$ occupancy and therefore directly affects the metal-adsorbate bond strength via the population of antibonding states. ${ }^{3,4}$ Due to linear relationships between the $d$-band shift and adsorption strength of various intermediates, the ORR activity can be simply modeled by considering only one intermediate, e.g. $\mathrm{O}_{\mathrm{ad}}$, as "descriptor", and a volcano-type relation between adsorption strength and electrocatalytic activity has been established using density functional theory (DFT) ${ }^{7,8}$ Nevertheless it remains challenging to confirm the underlying assumptions regarding structure and bonding at the catalyst surface with in situ experiments in a condensed electrolyte.

$\mathrm{Pt}-\mathrm{O}$ interactions can be probed via $\mathrm{O} 1 s$ core-level spectroscopies, ${ }^{9}$ but the low x-ray energies used in these techniques restrict the sample environment to ultrahigh vacuum (UHV) or low-pressure ( $\sim 5$ torr) gas. By contrast, high-energy x-rays used in absorption spectroscopy at the $\mathrm{Pt} L$ edges can readily penetrate liquid electrolytes. ${ }^{10-21}$ Recently, we demonstrated that high energy resolution fluorescence detection $\mathrm{x}$ ray absorption spectroscopy (HERFD XAS) at the Pt $L_{3}$ edge, applied to a well-defined $\mathrm{Pt}$ monolayer on a $\mathrm{Rh}(111)$ substrate, is a surface sensitive probe of $\mathrm{Pt}-\mathrm{O}$ surface interactions that can unambiguously differentiate between the chemisorption of oxygen-containing species and surface oxide formation. ${ }^{22}$ Moreover, the nature of Pt oxides and their formation mechanism at high potentials was found to be strongly influenced by the underlying metal substrate. ${ }^{23}$

By systematically studying Pt monolayers on a variety of M(111) substrates with HERFD XAS, we can directly probe the oxygen affinity of Pt "skin" layers under different strain and ligand effects; this is an important experimental complement on adsorption enthalpy calculations used in the volcano plot. In comparison of the latter with experimentally determined ORR activities for a number of bimetallic systems including Pt monolayer catalysts, ${ }^{8}$ we note two important characteristics: first, with the exception of the more recent development of $\mathrm{Pt}_{3} \mathrm{Sc}$ and $\mathrm{Pt}_{3} \mathrm{Y}$ catalysts, the materials near the top of the volcano are alloys of Pt with late $3 d$ transition metals, which can be unstable under fuel cell operating conditions due to dissolution of the non-noble component. Second, it is remarkable that some model catalysts, i.e. $\mathrm{Pt} / \mathrm{Au}(111)$, $\mathrm{Pt} / \mathrm{Ir}(111), \mathrm{Pt} / \mathrm{Rh}(111)$ and $\mathrm{Pt} / \mathrm{Ru}(0001),{ }^{24}$ appear much more active than predicted theoretically. This raises the question whether an additional catalyst design criterion besides ligand and strain effects can alter the oxygen adsorption energy, enhancing the ORR activity for these systems. 
Here, we show that such an enhancement can be due to three-dimensional nanostructuring of the Pt monolayer, which has not been accounted for in the previous studies, thus validating the theoretical predictions. Using the example of $\mathrm{Pt} / \mathrm{Rh}(111)$, we compare electrochemical and in situ HERFD XAS measurements in $0.01 \mathrm{M} \mathrm{HClO}_{4}$ electrolyte of two samples obtained with different $\mathrm{Pt}$ deposition techniques resulting in a uniform two-dimensional (2D) Pt layer and threedimensional (3D) Pt islands, respectively. Most remarkably, we find almost complete absence of electrochemical and spectral signatures of $\mathrm{O} / \mathrm{OH}_{\mathrm{ad}}$ and $\mathrm{H}_{\mathrm{ad}}$ on $2 \mathrm{D} \mathrm{Pt} / \mathrm{Rh}(111)$, which directly confirms the significant down-shift of the Pt $5 d$ band that leads to $0.6 \mathrm{eV}$ weaker $\mathrm{O}$ adsorption. The same vertical ligand and strain effects also weaken $\mathrm{O}$ and $\mathrm{H}$ adsorption on $3 \mathrm{D} \mathrm{Pt} / \mathrm{Rh}(111)$ but are partially compensated in a large number of adsorption sites with locally higher Pt thickness and under-coordinated $\mathrm{Pt}$ atoms at island edges and corners. We establish a linear scaling relationship for the oxygen adsorption energy where local Pt thickness and under-coordination effects can be described in a single parameter. For 3D Pt model islands whose structural parameters are compatible with the extended x-ray absorption fine structure (EXAFS) measured on $3 \mathrm{D} \mathrm{Pt} / \mathrm{Rh}(111)$, we find a wide-spread range of site-specific contributions to the ORR activity whose average is in reasonable agreement with an RDE measurement on $\mathrm{Pt} / \mathrm{Rh}(111){ }^{24}$ We predict that tailored $3 \mathrm{D} \mathrm{Pt} / \mathrm{Rh}(111)$ nanostructures with increased occurrence of the most active sites could exhibit strongly enhanced ORR activity.

\section{EXPERIMENTAL DETAILS}

2.1. Sample preparation. An $8 \mathrm{~mm}$ diameter commercial Rh(111) single-crystal (Surface Preparation Laboratory, Zaandam, The Netherlands) was cleaned under ultrahigh vacuum by repeated sputtering and annealing cycles. A homebuilt evaporator with resistive heating was used to deposit the Pt film while the sample temperature was held at $\sim 600 \mathrm{~K}$. The $\mathrm{Pt}$ coverage was monitored using changes in the CO thermal desorption spectra from the $\mathrm{Pt} / \mathrm{Rh}(111)$ surface. During the deposition, $\mathrm{Pt}$ atoms are incorporated into the topmost $\mathrm{Rh}$ layer to form a surface alloy with increasing Pt content and, eventually, a pure two-dimensional $\mathrm{Pt}$ overlayer. In a previous study by Duisberg et al., it was confirmed with ion scattering spectroscopy (ISS), which strictly probes only the first atomic layer, that the surface $\mathrm{Pt}$ content reaches $100 \%$ before $\mathrm{Pt}$ atoms nucleate in a second layer. ${ }^{25}$

For the redox displacement of a $\mathrm{Cu}$ monolayer with $\mathrm{Pt}$, the $\mathrm{Rh}(111)$ single crystal was prepared by flame annealing and subsequent cooling in a $\mathrm{H}_{2} / \mathrm{N}_{2}(5: 95)$ atmosphere. The crystal was then transferred into a nitrogen-filled glovebag where it was mounted in a hanging meniscus flow cell which allows for a rapid exchange of the electrolyte under potential control. A single linear potential sweep was then started from $+0.4 \mathrm{~V}$ $(\mathrm{Ag} / \mathrm{AgCl})$ in $1 \mathrm{mM} \mathrm{CuSO}_{4}+0.05 \mathrm{M} \mathrm{H}_{2} \mathrm{SO}_{4}$ solution at a scan rate of $10 \mathrm{mV} / \mathrm{s}$ in the cathodic direction, and the current peak arising from $\mathrm{Cu}$ underpotential deposition ${ }^{26,27}$ (upd) was monitored. Immediately after the completion of the $\mathrm{Cu}$ upd peak, i.e., deposition of $1 \mathrm{ML} \mathrm{Cu}$, the cell was flushed with the $\mathrm{Cu}-$ free supporting electrolyte $\left(0.05 \mathrm{M} \mathrm{H}_{2} \mathrm{SO}_{4}\right)$. Meanwhile, the cathodic potential sweep was continued to a final value of -0.4 $\mathrm{V}$ in order to prevent any dissolution of the $\mathrm{Cu}$ monolayer. In analogy to previous experiments ${ }^{28,29}$ which used the stabilization of a $\mathrm{Cu}$ upd layer on $\mathrm{Au}(111)$ in $\mathrm{Cu}$-free electrolyte, we are able to verify with cyclic voltammetry that the $\mathrm{Cu}$ layer remains stable and has the desired coverage of $1 \mathrm{ML}$. After the deposition of $1 \mathrm{ML} \mathrm{Cu}$ and its stabilization in $\mathrm{Cu}$-free supporting electrolyte, the $\mathrm{Rh}(111)$ sample was quickly transferred to a glass beaker where the polished surface was exposed to the Pt deposition solution ( $1 \mathrm{mM} \mathrm{K}_{2} \mathrm{PtCl}_{4}+0.05 \mathrm{M} \mathrm{H}_{2} \mathrm{SO}_{4}$ ) for ca. $30 \mathrm{~s}$.

2.2. In situ $x$-ray electrochemical cell. Subsequent to the Pt deposition, the sample was mounted into an in situ $\mathrm{x}$-ray electrochemical cell. Two different setups have been used in this study. A "thin layer" cell similar to setups which have been used earlier for electrochemical surface x-ray diffraction studies ${ }^{30}$ was used with $6 \mu \mathrm{m}$ mylar foil (Goodfellow) as x-ray window. The cell can be deflated to minimize the x-ray path length through the electrolyte solution. A disadvantage of this setup is the limitation of mass transport due to the thin electrolyte layer. We circumvented this problem by limiting the potential window to a range where the electrochemical currents under potentiostatic conditions are low. Furthermore, for every change of the potential the cell was inflated in order to provide a thick electrolyte layer above the sample. At each new potential value, the cell was kept inflated for at least 15 min in order to allow for potential-induced phase transitions to complete under thick-layer conditions before returning to the thin-layer mode for the next XAS measurement. Faster potential changes and higher electrochemical currents can be achieved in our "droplet" hanging meniscus cell, ${ }^{22}$ where a thick electrolyte layer is provided throughout the $\mathrm{x}$-ray measurement. Both cells provide a three-electrode configuration with $\mathrm{Pt}$ wire as the counter electrode and a leak-free $\mathrm{Ag} / \mathrm{AgCl}$ reference electrode. All electrode potentials were converted to the scale of the reversible hydrogen electrode (RHE).

All electrolytes were made from high-purity chemicals (70\% $\mathrm{HClO}_{4}$, Trace Select Ultra, Sigma-Aldrich and 95\% $\mathrm{H}_{2} \mathrm{SO}_{4}$, Trace Select, Sigma-Aldrich; 99.999\% $\mathrm{CuSO}_{4} \cdot 5 \mathrm{H}_{2} \mathrm{O}$, Sigma-Aldrich) and ultrapure water from a Millipore Gradient system.

2.3. X-ray absorption spectroscopy. All in situ X-ray absorption spectra were measured at the Stanford Synchrotron Radiation Lightsource (SSRL). At Beam Line 11-2, EXAFS measurements were carried out with conventional fluorescence detection using a large 30-element Ge solid state detector. HERFD-XANES measurements were performed at SSRL Beam Line 6-2 using a $\mathrm{Si}(111)$ monochromator in combination with a Rowland circle analyzer ${ }^{31}$ consisting of three spherically bent Ge perfect crystals $(R=1 \mathrm{~m})$. The crystals were aligned in a backscattering geometry using the (660) Bragg reflection at $80.0^{\circ}$ to select the Pt $L \alpha_{1}$ fluorescence line $(9442 \mathrm{eV})$. The combined resolution of the monochromator and analyzer as determined by measuring the elastic scattering was $1.6 \mathrm{eV}$. Assuming an intrinsic monochromator resolution of $\sim 1.3 \mathrm{eV}$ the analyzer resolution is estimated to be $\sim 1 \mathrm{eV}$.

For all XAS measurements, the incidence angle of the X-ray beam to the $\mathrm{Pt} / \mathrm{Rh}(111)$ surface was adjusted to the critical angle for total external reflection, thereby enhancing the fluorescence intensity up to fourfold. ${ }^{32}$ The orientation of the electric field vector of the incident beam was perpendicular to the surface normal.

For the EXAFS data analysis, SIXPack ${ }^{33}$ was used for background subtraction, spline fitting and least-square fitting of the Fourier-transformed EXAFS signal. Backscattering phase and amplitude functions required for fitting of spectra were obtained from FEFF $6 .^{34}$ 
2.4. Computational methods. All HERFD XAS calculations were carried out using the FEFF 8.4 program, which employs a full multiple-scattering formalism. ${ }^{35}$ By using the "NOHOLE" card, potentials and phase shifts were calculated assuming complete screening of the core-hole, resulting in better agreement with experimental white-line intensities. This is fully consistent with previously reported FEFF results on transition metal $L_{2}$ and $L_{3}$ edges. ${ }^{10,36-39}$ The line-sharpening effect observed in HERFD was modeled by reducing the theoretical lifetime broadening by $1.75 \mathrm{eV}$ using the "EXCHANGE" card. This value was determined by comparing the computed XANES spectrum of a clean $\mathrm{Pt} / \mathrm{Rh}(111)$ surface with an experimental spectrum at a potential corresponding to the double-layer region, namely $E=+0.4 \mathrm{~V}$. More detailed information about the model structures and input parameters for the FEFF8 calculations are provided in the Supporting Information.

2.5 DFT calculations. All DFT calculations were performed using GPAW ${ }^{40,41}$ within the ASE environment ${ }^{42}$ using the RPBE functional for exchange and correlation. ${ }^{43}$ The standard PAW setups and double-zeta polarized basis set provided with GPAW were used. $^{44}$ We used a grid spacing of $0.18 \AA$, and a Brillouin zone sampling of $2 \times 2$ k-points along the periodic directions. $\mathrm{O}$ adsorption energies were calculated on small Pt clusters supported on the (111) fcc surface of Rh. The cluster adheres to the surface such that the Pt atoms all coincide with substrate lattice sites. The lattice constant was optimized with the Rh substrate using a separate DFT calculation. O binding energies were calculated on each fcc hollow site on the (111) plane of the Pt cluster. No geometry optimization has been used. The $\mathrm{O}$ atom was always kept at a distance of $2.07 \AA$ from the neighboring Pt atoms. The unit cell for the fcc surface of Rh contains 8 by 8 atoms in an orthorhombic cell and has 5 layers. $5 \AA$ of vacuum is added between the non-periodic cell boundary and the atom closest to that boundary.

\section{RESULTS AND DISCUSSION}

It is well-known that the fabrication of well-defined metal monolayers can be challenging, especially in the case of $\mathrm{Pt}$ which in general, due to its high surface energy, ${ }^{45}$ is likely to tend towards a Volmer-Weber growth mode rather than the desired fully two-dimensional growth of one monolayer. However, on substrates with higher surface energies than Pt, such as $\mathrm{Rh}, \mathrm{Ru}$ or $\mathrm{Ir}^{45}$ one would expect a growth mode of either the Frank-van der Merwe or Stranski-Krastanov type to be favored, i.e. at least up to a coverage of $1 \mathrm{ML}, \mathrm{Pt}$ would grow in a single $2 \mathrm{D}$ layer. The latter has been confirmed for the growth of Pt under UHV conditions on $\mathrm{Rh}(111)^{25}$ and $\mathrm{Ru}(0001) .{ }^{46}$ While a well-defined 2D Pt monolayer was successfully prepared in ultrahigh vacuum (UHV) by Pt vapor deposition, we discovered that 3D island growth occurs when an electrochemical preparation is chosen, which consists of the redox displacement of an underpotential deposited (upd) $\mathrm{Cu}$ monolayer. $^{24,47}$

The morphology of the deposited Pt layers on Rh(111) was determined for both UHV and electrochemically prepared samples using in situ $\mathrm{Pt} L_{3}$ extended x-ray absorption fine structure (EXAFS), recorded at potentials close to hydrogen evolution. The Fourier transformed EXAFS magnitudes for both samples are shown in Figure 1a and b. Least-square fitting with $\mathrm{Pt}-\mathrm{Pt}$ and $\mathrm{Pt}-\mathrm{Rh}$ nearest-neighbor coordination shells gives coordination numbers (Table 1) that can be used to determine the film morphology. For the vapor deposited sample, we found very good agreement with a pseudomorphic Pt layer of $1 \mathrm{ML}$ thickness which uniformly covers the Rh surface. In contrast, the significantly smaller Pt-Rh coordination number in the redox-displacement sample indicates the three-dimensional nature of the deposit where only $\sim 50 \%$ of the $\mathrm{Pt}$ atoms are in direct contact with the $\mathrm{Rh}$ substrate. Since the $\mathrm{Pt}-\mathrm{Pt}$ coordination number, at the same time, is also significantly below values that would be expected for a uniform bilayer or multilayers, there must be a large number of undercoordinated Pt atoms. The observed coordination numbers can be explained with a model structure consisting of threedimensional islands. After a detailed consideration of various island model structures (Supporting Information) we find agreement with the EXAFS results for $3 \mathrm{D} \mathrm{Pt} / \mathrm{Rh}(111)$ within experimental error bars for islands of which the most range from two to four layers thickness and $\sim 1$ to $\sim 4 \mathrm{~nm}$ lateral width. This range of island widths is in very good agreement with the sizes of Pt islands that can be seen in an in situ STM measurement ${ }^{47}$ of $\mathrm{Pt} / \mathrm{Rh}(111)$, where the same redoxdisplacement technique was employed.

Table 1: In situ EXAFS fitting results

\begin{tabular}{llll}
\hline & Pt-Pt & Pt-Rh & $R$ factor \\
\hline 2D Pt/Rh(111) & & & 0.0282 \\
$N$ & $6.5 \pm 0.8$ & $3.2 \pm 0.7$ & \\
$R(\AA)$ & $2.72 \pm 0.02$ & $2.72 \pm 0.02$ & \\
$\sigma^{2}\left(\AA^{2}\right)$ & 0.005 & 0.005 & \\
\hline 3D Pt/Rh(111) & & & 0.0238 \\
$N$ & $7.3 \pm 0.7$ & $1.4 \pm 0.5$ & \\
$R(\AA)$ & $2.74 \pm 0.02$ & $2.68 \pm 0.05$ & \\
$\sigma^{2}\left(\AA^{2}\right)$ & 0.005 & 0.005 & \\
\hline
\end{tabular}

a Data range: $k=3.0-9.8 \AA^{-1}$.

bata range: $k=3.0-9.5 \AA^{-1}$.

The near-edge region (XANES) of $\mathrm{Pt} L_{3}$ spectra shows a characteristic absorption maximum ("white-line") due to $2 p \rightarrow 5 d$ transitions and thus provides a probe of the unoccupied part of the Pt $5 d$ band. ${ }^{48,49}$ The information about the energy distribution of unoccupied $d$ states is limited by the Pt $2 p$ core hole lifetime broadening, but significantly sharpened spectral features can be obtained in the High Energy Resolution Fluorescence Detection (HERFD) mode ${ }^{36,50}$ which we used in our experiment. The HERFD technique, together with the use of well-defined single-crystal samples and sufficiently large model structures in the multiple-scattering computations, eliminates uncertainties in the interpretation of in situ XAS, in particular at high electrochemical potentials where contradictory models of $\mathrm{Pt}-\mathrm{O}$ interactions have been proposed. ${ }^{11-20}$ 
(a)

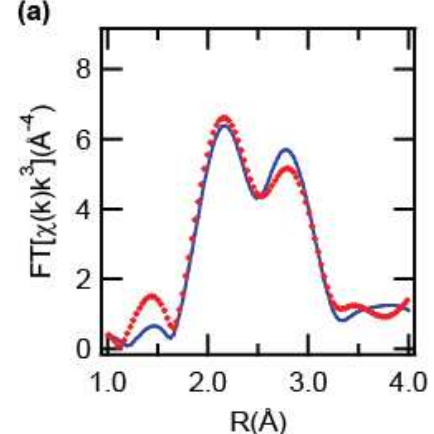

(b)
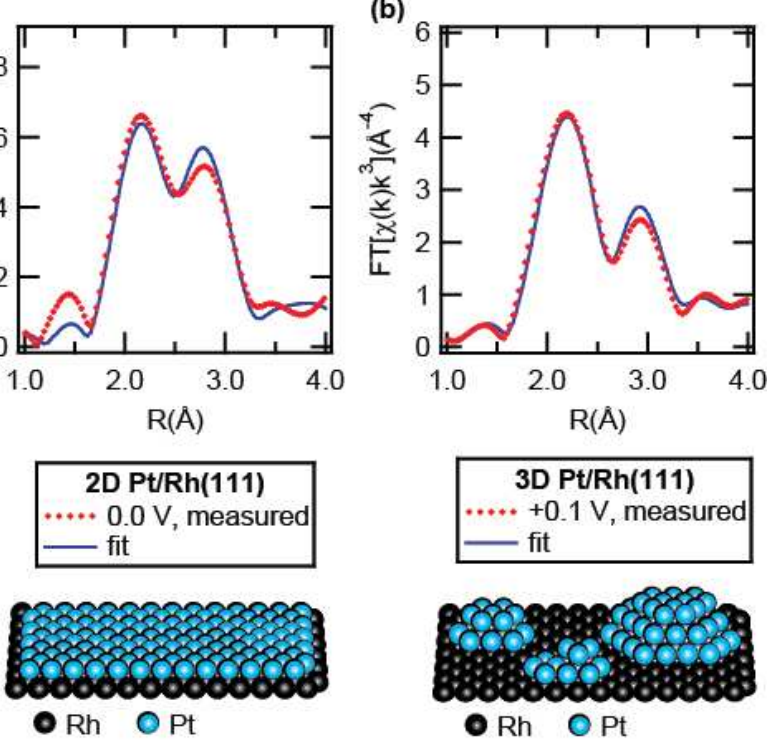

(a)

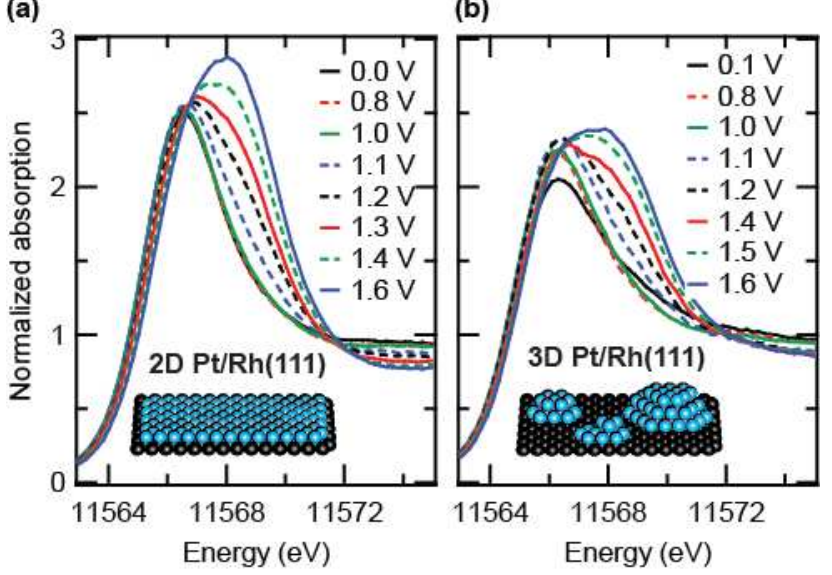

Figure 2. In situ Pt $L_{3}$ HERFD XAS for $1 \mathrm{ML} \mathrm{Pt/Rh(111)} \mathrm{in} 0.01$ $\mathrm{M} \mathrm{HClO}_{4}$ : (a) 2D Pt film, (b) 3D Pt islands. Spectra were recorded in the order of increasing electrochemical potentials.

(a)

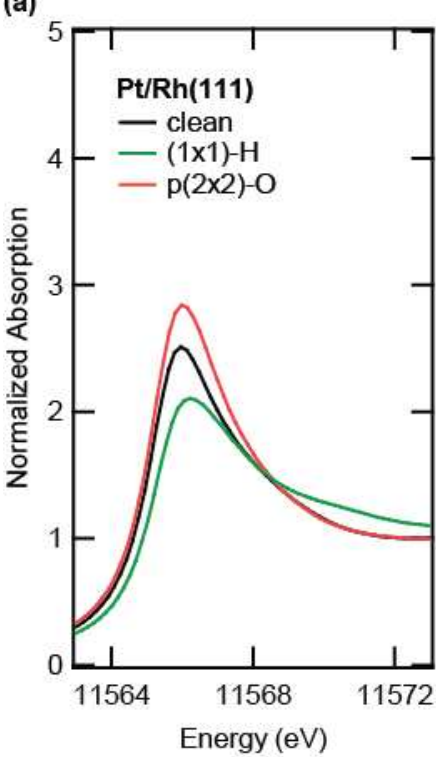

(b)

Figure 1. Morphology determination for $\mathrm{Pt} / \mathrm{Rh}(111)$ using EXAFS. Fourier transforms of measured in situ EXAFS, fitting results for (a) UHV evaporated $\mathrm{Pt} / \mathrm{Rh}(111)$, (b) $\mathrm{Pt} / \mathrm{Rh}(111)$ prepared by redox displacement of a $\mathrm{Cu}$ upd layer. Bottom of (a) and (b): schematic structure models.

HERFD XAS spectra of both samples in $\mathrm{N}_{2}$-saturated 0.01 $\mathrm{M} \mathrm{HClO}_{4}$ (Figure 2) were recorded in situ in order of increasing potential with respect to the reversible hydrogen electrode (RHE). After increasing the potential to $1.1 \mathrm{~V}$ and higher values, both samples consistently show a strong broadening and intensity increase of the white-line and intensity decrease at energies just above the white-line region, which we identified earlier as unambiguous signature of Pt oxide formation. ${ }^{22} \mathrm{Be}-$ sides, the two samples show significant differences, both in the overall white-line intensities that are generally larger for the 2D Pt layer (Figure 2a), as well as in the potentialdependent changes of white-line shape and intensity. Additional changes can be seen for the 3D Pt islands (Figure 2b) in two potential regions. At potentials close to hydrogen evolution, a reduction of the peak intensity together with a significant shoulder on the high energy side $(\sim 11570 \mathrm{eV})$ of the white-line is caused by chemisorbed H. A subtle increase of the peak intensity at $11566 \mathrm{eV}$ occurs at potentials just below $1.1 \mathrm{~V}$, which is due to $\mathrm{O}$ or $\mathrm{OH}$ adsorption. As shown in Figure $3 \mathrm{a}$, this interpretation of the spectral changes can be qualitatively confirmed with $a b$ initio multiple-scattering calculations on model structures of $\mathrm{H} / \mathrm{Pt} / \mathrm{Rh}(111)$ and $\mathrm{O} / \mathrm{Pt} / \mathrm{Rh}(111)$ using the FEFF8 code. ${ }^{35}$ It is important to note that $\mathrm{O}$ chemisorption causes only an increase of the peak at $11566 \mathrm{eV}$ with no significant broadening. This is in strong contrast to the spectral signatures of Pt oxides (Figure $3 b$ ), where the white line has much higher integrated intensity and is shifted towards higher energy.

The assignment of the $\mathrm{Pt}-\mathrm{H}$ signature is also in agreement with previous studies where Pt nanoparticles were used in the measurements, although the corresponding FEFF calculations were employing a very small $\mathrm{Pt}_{6}$ cluster. $^{21}$

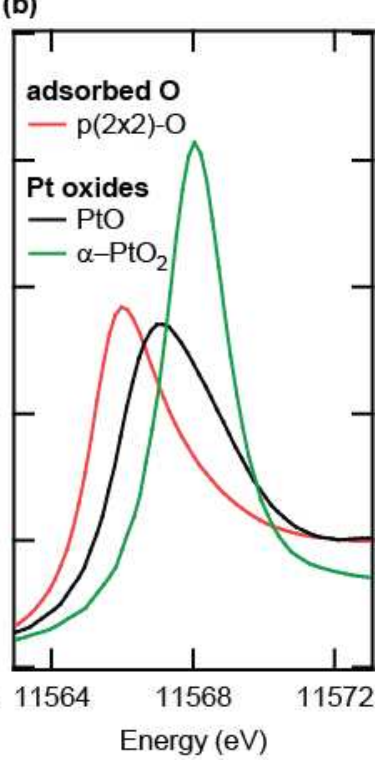

Figure 3. Calculated HERFD XAS, using the FEFF8 code, for

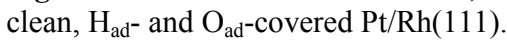

In order to represent the measured spectral changes quantitatively, we performed a deconvolution using an arctangent function to model the absorption edge and two Gaussian profiles to represent the white-line peak, respectively. We kept the energy position of each component and the width and step height of the arctangent function at fixed values and allowed only the widths and intensities of the Gaussian functions to vary with the potential. For all spectra, good fitting results with reduced $\chi^{2}$ values better than 0.0006 could thus be obtained. The results for both samples including their uncertainties are shown in Figure 4. The white line for both samples at potentials below $1.1 \mathrm{~V}$ can be fitted with a sharp "main" peak at $\sim 11566 \mathrm{eV}$ and a broad peak at $11568.4 \mathrm{eV}$ representing the high-energy shoulder. At $1.1 \mathrm{~V}$, Pt oxide formation causes the higher energy component to become significantly sharper and more intense, and upon further potential increase it eventually exceeds the intensity of the component at lower energy. 


\section{(a) \\ 2D Pt/Rh(111)}

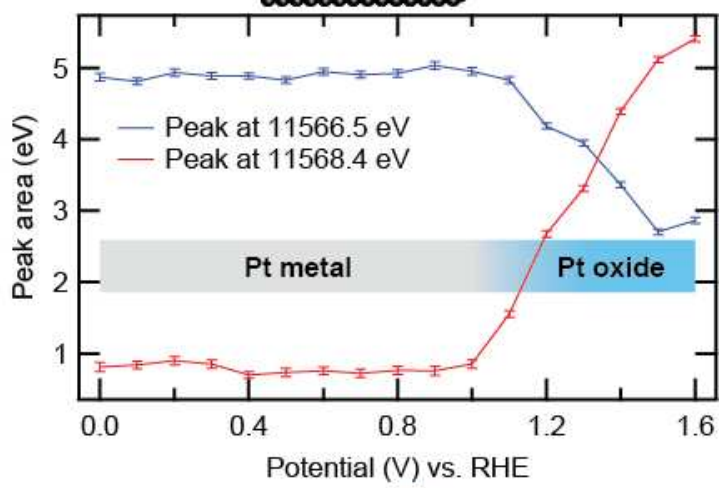

(b)

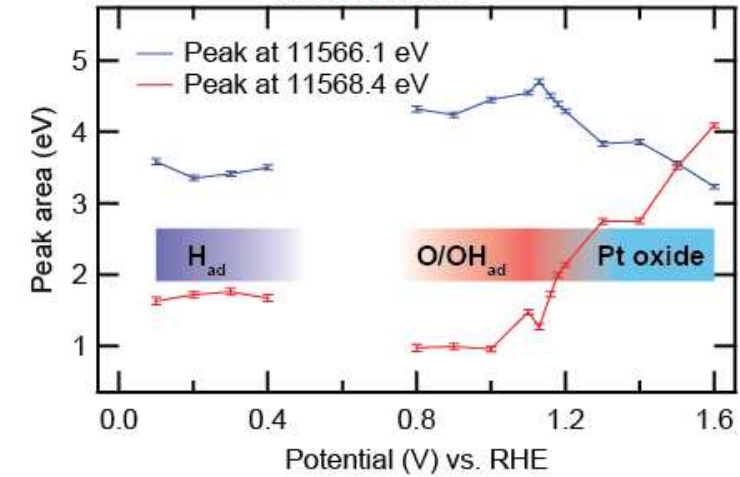

(c)

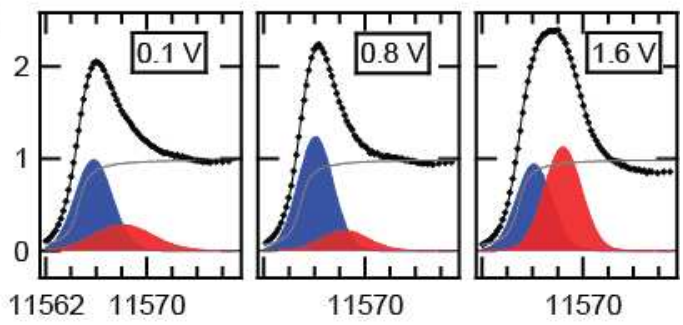

Figure 4. Deconvolution of in situ HERFD XAS of $\mathrm{Pt} / \mathrm{Rh}(111)$ in $0.01 \mathrm{M} \mathrm{HClO}_{4}$. While only the Pt metal-to-oxide transition can be identified for the 2D Pt layer (a), the 3D deposit (b) shows additional spectral signatures due to $\mathrm{H}_{\mathrm{ad}}$ and $\mathrm{O} / \mathrm{OH}_{\mathrm{ad}}$. Three representative fitting results for $3 \mathrm{D} \mathrm{Pt} / \mathrm{Rh}(111)$ are shown in (c) using the same colors as in (b) for the peak areas, and a gray line for the arctangent function.

Two additional phase transitions with more subtle spectral features appear on the 3D Pt islands: at low potentials, the signature of chemisorbed hydrogen can be clearly seen in the depressed peak at $11566 \mathrm{eV}$ and stronger peak at $11568 \mathrm{eV}$, and a subtle increase of the component at $11566 \mathrm{eV}$ as the potential is raised from $0.8 \mathrm{~V}$ to $1.13 \mathrm{~V}$ indicates $\mathrm{O} / \mathrm{OH}$ chemisorption. Both these changes are virtually absent for the $2 \mathrm{D} \mathrm{Pt}$ sample. The suppression of features induced by $\mathrm{Pt}-\mathrm{H}$ and $\mathrm{Pt}-$ $\mathrm{O}$ can only be explained when we assume significantly lower adsorbate coverages on the 2D Pt layer.

This interpretation is further supported by the comparison of cyclic voltammetry (CV) curves for $2 \mathrm{D} \mathrm{Pt} / \mathrm{Rh}(111)$ and $3 \mathrm{D}$ $\mathrm{Pt} / \mathrm{Rh}(111)$ (Figure 5). In the $\mathrm{CV}$ of $2 \mathrm{D} \mathrm{Pt} / \mathrm{Rh}(111)$, we observe that both onsets of $\mathrm{H}_{\mathrm{ad}}$ and $\mathrm{O} / \mathrm{OH}_{\mathrm{ad}}$ formation are significantly shifted outwards with respect to the potential window between 0 and $1.0 \mathrm{~V}$, resulting in strongly reduced adsorbate coverages as compared to $\mathrm{Pt}(111)$. By contrast, the $\mathrm{CV}$ of $3 \mathrm{D}$
$\mathrm{Pt} / \mathrm{Rh}(111)$ has much more pronounced features towards both ends of the potential window. The broad shape of the anodic current increase due to $\mathrm{O} / \mathrm{OH}_{\mathrm{ad}}$ formation indicates the presence of (100) or (110) facets, further supporting the proposed 3D island model. The large width of the potential range of $\mathrm{O} / \mathrm{OH}$ adsorption can also explain why the corresponding changes in HERFD XAS are more difficult to detect than the spectral signature of $\mathrm{H}_{\text {ad }}$.

In order to further elucidate the effect of nanostructure and local coverage on the shape of the CVs, we prepared an additional $\mathrm{Pt} / \mathrm{Rh}(111)$ sample in UHV with a coverage of $3 \mathrm{ML} \mathrm{Pt}$. In this case, also shown in Figure 5, the inward shift of both $\mathrm{H}_{\mathrm{ad}}$ and $\mathrm{O} / \mathrm{OH}_{\mathrm{ad}}$ features at the cost of the double layer range can be clearly seen, without significant additional features from the contribution of (100) or (110) facets. Even for $3 \mathrm{ML}$ $\mathrm{Pt} / \mathrm{Rh}(111)$, however, the double layer range with an adsorbate-free or $\mathrm{H}_{2} \mathrm{O}$-covered $\mathrm{Pt}$ surface is wider than for pure $\operatorname{Pt}(111) ;{ }^{51}$ this can be attributed to the strain effect.

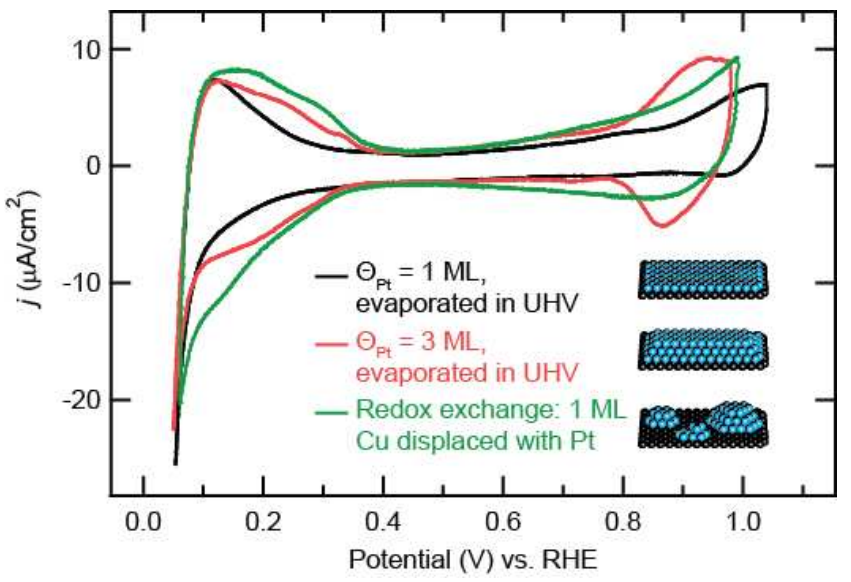

Figure 5. Cyclic voltammograms of UHV-evaporated $\mathrm{Pt} / \mathrm{Rh}(111)$ samples with two different thicknesses (2D Pt/Rh(111), $\Theta_{\mathrm{Pt}_{\mathrm{t}}}=1$ $\mathrm{ML}$, and $\Theta_{\mathrm{Pt}}=3 \mathrm{ML}$ ), and 3D Pt/Rh(111).

Our voltammetry results for UHV-prepared $\mathrm{Pt} / \mathrm{Rh}(111)$ samples with different Pt layer thickness show exactly the same trend as a combined UHV-STM and voltammetry study of similar Pt layers where a $\mathrm{Ru}(0001)$ substrate was used. ${ }^{46}$ Both these experimental findings confirm the DFT-based prediction that $1 \mathrm{ML} \mathrm{Pt}$ on $\mathrm{Rh}(111)$ and $\mathrm{Ru}(0001)$ adsorb $\mathrm{O} \sim 0.6$ and $\sim 0.7 \mathrm{eV}$ more weakly than $\operatorname{Pt}(111)$, respectively. ${ }^{8}$ These adsorption energy changes correspond to positive shifts of the equilibrium potential for $\mathrm{O}_{\mathrm{ad}}$ of $\sim 0.3 \mathrm{~V}$ and $\sim 0.35 \mathrm{~V}$ for $1 \mathrm{ML}$ $\mathrm{Pt}$ on $\mathrm{Rh}(111)$ and $\mathrm{Ru}(0001)$, respectively. Approximately the same potential shifts can be expected for $\mathrm{OH}_{\mathrm{ad}}$ due to the scaling relationship between $\mathrm{O}$ and $\mathrm{OH}$ adsorption energies. ${ }^{52}$

In order to estimate $\mathrm{O}$ adsorption energies on 3D $\mathrm{Pt} / \mathrm{Rh}$ (111), extensive DFT calculations were carried out using 12 model structures (Figure 6) representing different local Pt coverage, as well as different proximity of the $\mathrm{O}$ fcc threefold hollow adsorption site to surrounding Pt and Rh atoms and vacancy sites. Two effects can be seen: the weakening of the $\mathrm{O}$ adsorption energy compared to pure $\operatorname{Pt}(111), \Delta E_{\mathrm{O}}$, is attenuated by $\sim 0.1 \mathrm{eV}$ when we increase the local Pt thickness from 1 to $2 \mathrm{ML}$, and $\mathrm{O}$ adsorption is further enhanced when we move the fcc threefold hollow adsorption site from the center of the island to the proximity of an edge with undercoordinated Pt atoms. To disentangle ligand, strain and local 
under-coordination effects, we carried out a simple linear regression analysis to correlate the $\mathrm{O}$ binding energy with the average coordination numbers $N_{\mathrm{Pt}}^{\mathrm{S}}$ and $N_{\mathrm{Rh}} \mathrm{s}$ of $\mathrm{Pt}$ and $\mathrm{Rh}$ surrounding the three $\mathrm{Pt}$ atoms that constitute the adsorption site. We found the binding energy of $\mathrm{O}$ to scale linearly with an effective coordination number given by $N_{\mathrm{eff}}^{\mathrm{S}}=N_{\mathrm{Pt}}^{\mathrm{S}}+1.09$ $N_{\mathrm{Rh}}{ }^{\mathrm{S}}$. The coefficient for $N_{\mathrm{Rh}}$ s represents the ligand effect which in the case of $\mathrm{Rh}$ weakens the metal-oxygen bond more strongly than Pt.

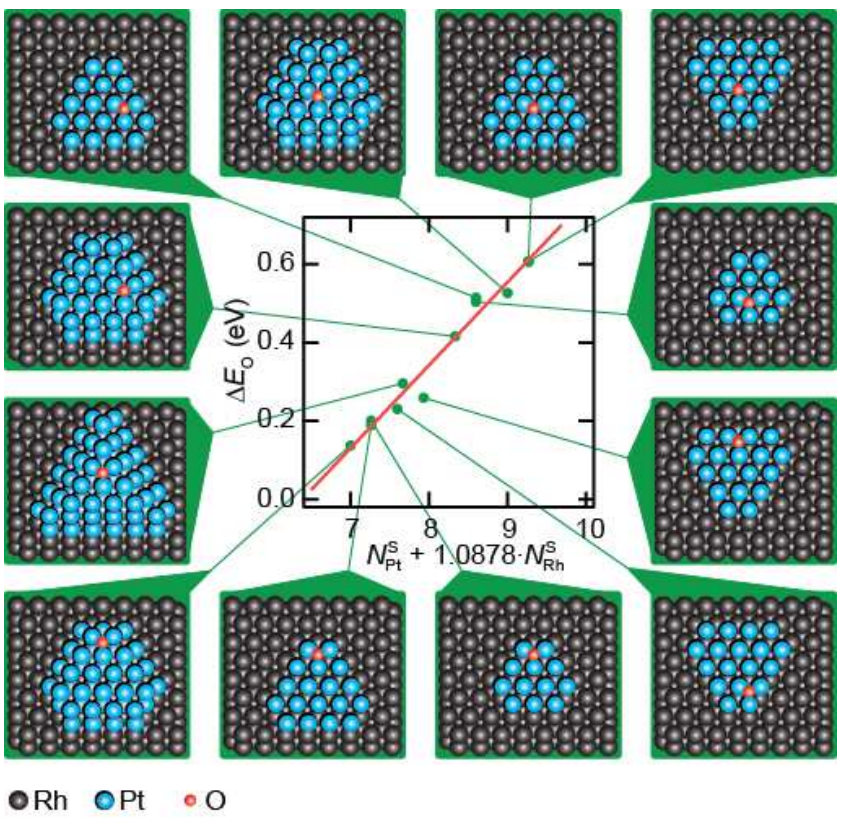

Figure 6. DFT calculations of the adsorption energy $\Delta E_{\mathrm{O}}$ of a single $\mathrm{O}$ atom on $\mathrm{Pt} / \mathrm{Rh}(111)$ model structures, shown as relative values compared to $\operatorname{Pt}(111)\left(\Delta E_{\mathrm{O}, \mathrm{Pt}(111)}=0\right)$. The corresponding adsorption energy for each structure is plotted as a function of the effective coordination number around the $\mathrm{O}$ adsorption site, and a linear fit (red line) is shown. The linear relationship can be used to estimate $\Delta E_{\mathrm{O}}$ for any other fcc threefold hollow site on Pt islands with various shapes and sizes.

This relation also serves as a guiding principle to determine the electrocatalytic activity for different morphologies of nanostructures as it gives a simple way to correlate the oxygen binding energy to an easily calculable geometric parameter. Although this linear relationship is surprisingly simple, its validity becomes evident when we consider that (i) it predicts approximately the same gain in adsorption energy near island edges as an earlier model for $\mathrm{O}$ adsorption near step edges on $\operatorname{Pt}(111) ;^{53}$ (ii) it predicts no significant ligand effect beyond 1 ML local Pt thickness; this result is similar to the calculation of $\mathrm{H}$ adsorption energies on $\mathrm{Pt} / \mathrm{Ru}(0001)$ where the ligand effect becomes very small already for 2 ML Pt.

The linear correlation in Figure 6 can be applied to all possible fcc threefold hollow sites (Supporting Information) that can occur within the 3D Pt island morphology determined with EXAFS. The contribution of each individual site to the overall ORR activity can be estimated using the volcano relationship ${ }^{8}$ with $\Delta E_{\mathrm{O}}$, and directly compared with the previous $\mathrm{RDE}$ measurement on $\mathrm{Pt} / \mathrm{Rh}(111)$ (Figure $7 \mathrm{a}){ }^{24}$ Although we can only speculate about the precise size and shape distribution of 3D Pt islands in our sample and the corresponding occurrence of adsorption sites, it appears that the average of site- specific ORR activity contributions is reasonably close to the experimental value.

We propose that a kinetically controlled $3 \mathrm{D}$ growth mode can be generalized for $\mathrm{Pt} / \mathrm{M}(111)(\mathrm{M}=\mathrm{Au}, \mathrm{Pd}, \mathrm{Rh}, \mathrm{Ir})$ and $\mathrm{Pt} / \mathrm{Ru}(0001)$ monolayer catalysts prepared by the redoxdisplacement technique, ${ }^{24}$ this explains why their measured ORR activities, which are also shown in Figure $7 \mathrm{a}$, deviate from the prediction, where a 2D Pt layer was assumed, ${ }^{8}$ towards pure $\mathrm{Pt}$. In the $\mathrm{Pt} / \mathrm{Au}(111)$ system, potential-dependent $\mathrm{Pt} / \mathrm{Au}$ place exchange reactions ${ }^{54}$ could further add complexity.

It is remarkable that the contribution of under-coordinated sites exceeds that of removing the vertical ligand effect and can even shift $\Delta E_{\mathrm{O}}$ for individual adsorption sites almost exactly to $0.20 \mathrm{eV}$ where the volcano reaches its maximum. ${ }^{8}$ Since such an "optimal" adsorption site near the top corners of islands is in close proximity of a more strongly adsorbing bridge or fourfold hollow site, we assume that it cannot be occupied due to repulsive $\mathrm{O}-\mathrm{O}$ interactions. Nevertheless, we can identify two other types of fcc threefold hollow sites that could offer a $\sim 9.5$-fold activity enhancement over a midterrace fcc site on $\mathrm{Pt}(111)$. These two most active sites can be found along island edges of the "B" type which separate two adjacent (111) facets. Their occurrence could be maximized through shape-selective nanofabrication of bilayer Pt islands as shown with a representative example in Figure $7 \mathrm{~b}$. We also show predicted ORR activities for a series of bilayer islands of analogous shape but with different lateral widths; a detailed description of the underlying analysis is given in the Supporting Information. Within the series in Figure $7 \mathrm{~b}$, only midterrace sites and the two most active types of near-B-edge sites contribute to the ORR activity. Since the number of midterrace sites grows faster than that of near-edge sites with increasing island width, the smallest islands exhibit the strongest ORR enhancement of up to 5-fold over Pt(111). Such high ORR activities have been reached with $\mathrm{Pt}_{3} \mathrm{Co}$ and $\mathrm{Pt}_{3} \mathrm{Ni}$ alloys, ${ }^{55}$ but a $\mathrm{Pt} / \mathrm{Rh}$ catalyst offers much higher resistance against degradation due to the combination of two metals with high cohesion energy and stability against dissolution. While the use of $\mathrm{Rh}$ as catalyst component is unlikely to be costefficient, the same design principle could be used for other bimetallic combinations of $\mathrm{Pt}$ with more abundant materials, exploiting the advantage of catalyst stability through high cohesion energy, and at the same time compensating a $d$-band shift towards weaker $\mathrm{O}$ adsorption by generating tailored nanostructures with under-coordinated $\mathrm{Pt}$ sites.

\section{CONCLUSION}

Due to the design of the model catalyst and the reduced lifetime broadening in the HERFD mode employed here, our in situ XAS measurements on $\mathrm{Pt} / \mathrm{Rh}(111)$ monolayer electrocatalysts reveal the subtle spectral features of chemisorbed $\mathrm{O} / \mathrm{OH}$ more clearly than conventional XAS. Thus, the previous uncertainties in distinguishing $\mathrm{O} / \mathrm{OH}$ from Pt surface oxide have been overcome. Moreover, our experimental results clearly and consistently show significant differences in surface morphology and chemisorption behavior as a result of the two sample preparation techniques employed here. 
(a)

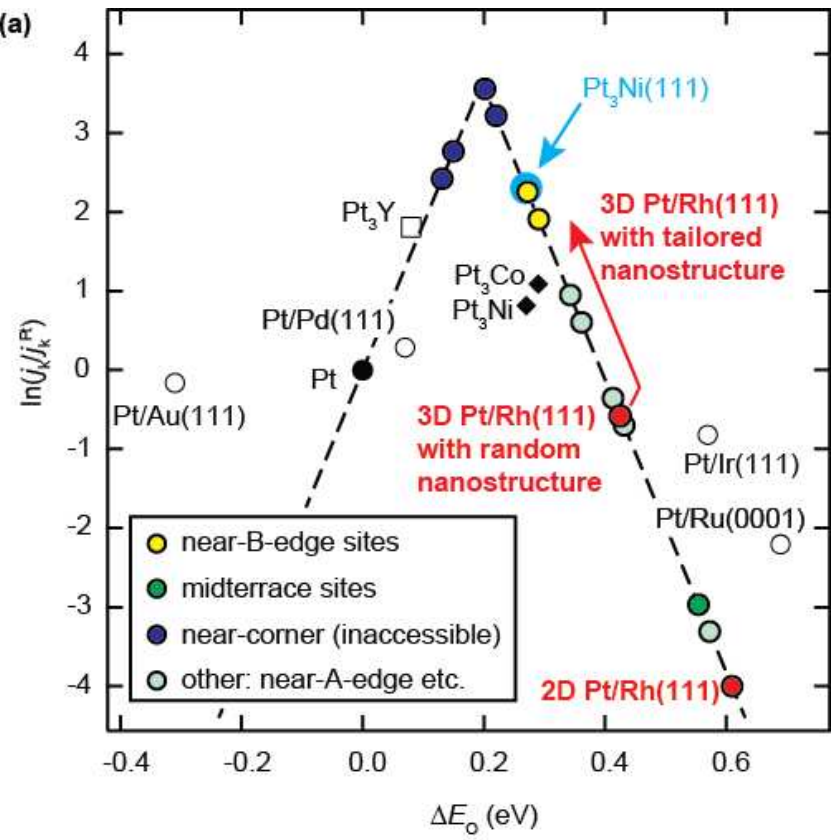

(b)

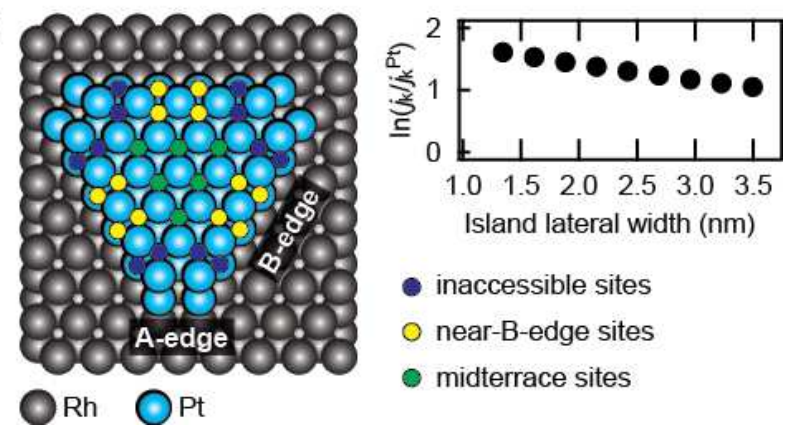

Figure 7. (a) Predicted individual ORR activities of individual fcc threefold hollow sites on 3D Pt/Rh(111). For comparison, measured ORR activities are shown for a range of bimetallic electrocatalysts ${ }^{5,8,24}$ including the previous measurement on 3D $\mathrm{Pt} / \mathrm{Rh}(111) .{ }^{24}$ The latter can be considered to represent a weighted average of the individual site contributions plotted with light green, dark green and yellow markers. (b) Bilayer islands with maximized occurrence of near-B-edge sites (yellow). The graph shows the ORR activity enhancement for a series of such islands whose lateral width is varied by changing the length of the Bedges while the A- edges are fixed at $0.54 \mathrm{~nm}$ length.

DFT calculations have predicted before and confirm here that atomic oxygen is bound to a Pt monolayer supported on $\mathrm{Rh}(111) \sim 0.6 \mathrm{eV}$ more weakly than to the surface of pure $\mathrm{Pt} ;{ }^{8}$ this is due to a shift of the $d$-band center to lower energy caused by strain and vertical ligand effects. Three-dimensional $\mathrm{Pt}$ islands on $\mathrm{Rh}(111)$ show significantly higher affinity to chemisorbed $\mathrm{H}$ at low potentials and $\mathrm{O} / \mathrm{OH}$ at high potentials than the two-dimensional monolayer on the same substrate. This can be explained with two cooperative effects that both cause an up-shift of the Pt $5 d$-band and a corresponding increase of adsorption enthalpies for both $\mathrm{H}$ and $\mathrm{O} / \mathrm{OH}$. The higher local thickness (2-4 ML as determined from EXAFS) in $3 \mathrm{D} \mathrm{Pt} / \mathrm{Rh}(111)$ removes to a great extent the vertical ligand effect, leaving only the strain effect. Hence, the $d$-band center is shifted back from the calculated position for $2 \mathrm{D} \mathrm{Pt} / \mathrm{Rh}(111)$ towards that for pure Pt, resulting in an increase of both $\mathrm{Pt}-\mathrm{O}$ and $\mathrm{Pt}-\mathrm{H}$ bond strengths.
The high amount of edges and corners in the $3 \mathrm{D}$ island nanostructure adds further enhancements in $\mathrm{O}$ affinity in a very similar manner to stepped $\mathrm{Pt}(111)$ surfaces. ${ }^{53}$ This can overcompensate ligand and strain effects, thus opening a new field of catalyst design through nanostructuring, where catalytic activity becomes much less dependent from the choice of constituent elements. Hence, the often encountered incompatibility between catalyst activity and stability could be overcome.

\section{ASSOCIATED CONTENT}

Supporting Information. Detailed consideration of model structures for the EXAFS interpretation; details of FEFF8 calculations; calculated ORR activities for various Pt islands on $\mathrm{Rh}(111)$.

\section{AUTHOR INFORMATION}

\section{Corresponding Author}

*dfriebel@slac.stanford.edu, nilsson@slac.stanford.edu

\section{Author Contributions}

The manuscript was written through contributions of all authors. All authors have given approval to the final version of the manuscript.

\section{Funding Sources}

This work is supported by the Department of Energy, Office of Basic Energy Sciences, Division of Materials Sciences and Engineering, under contract DE-AC02-76SF00515 and Division of Chemical Sciences through the SUNCAT Center for Interface Science and Catalysis.

\section{ACKNOWLEDGMENT}

This work is supported by the Department of Energy, Office of Basic Energy Sciences, Division of Materials Sciences and Engineering, under contract DE-AC02-76SF00515 and Division of Chemical Sciences through the SUNCAT Center for Interface Science and Catalysis. This research was partly carried out at the Stanford Synchrotron Radiation Lightsource, a National User Facility operated by Stanford University on behalf of the U.S. Department of Energy, Office of Basic Energy Sciences. D. F. is grateful to the Alexander von Humboldt Foundation for a Feodor Lynen Fellowship. The Center for Atomic-Scale Materials Design is funded by the Lundbeck Foundation. We acknowledge support from the Danish Center for Scientific Computing.

\section{ABBREVIATIONS}

$\mathrm{CV}$, cyclic voltammogram; DFT, density functional theory; EXAFS, extended x-ray absorption fine structure; HERFD, high energy resolution fluorescence detection; ML, monolayer; ORR, oxygen reduction reaction; RHE, reversible hydrogen electrode; UHV, ultra-high vacuum; XAS, x-ray absorption spectroscopy.

\section{REFERENCES}

(1) Hammer, B.; Norskov, J. K. Nature 1995, 376, 238-240.

(2) Hammer, B.; Nørskov, J. K. Surf. Sci. 1995, 343, 211-220.

(3) Nilsson, A.; Pettersson, L. G. M.; Hammer, B.; Bligaard, T.; Christensen, C. H.; Nørskov, J. K. Catal. Lett. 2005, 100, 111-114.

(4) Strasser, P.; Koh, S.; Anniyev, T.; Greeley, J.; More, K.; Yu, C.; Liu, Z.; Kaya, S.; Nordlund, D.; Ogasawara, H.; Toney, M. F.; Nilsson, A. Nature Chem. 2010, 2, 454-460.

(5) Stamenkovic, V. R.; Fowler, B.; Mun, B. S.; Wang, G. F.; Ross, P. N.; Lucas, C. A.; Markovic, N. M. Science 2007, 315, 493497.

(6) Wang, C.; Chi, M.; Li, D.; Strmenik, D.; van der Vliet, D.; Wang, G.; Komanicky, V.; Chang, K.-C.; Paulikas, A. P.; Tripkovic, 
D.; Pearson, J.; More, K. L.; Markovic, N. M.; Stamenkovic, V. R. J. Am. Chem. Soc. 2011, 133, 14396-14403.

(7) Nørskov, J. K.; Rossmeisl, J.; Logadottir, A.; Lindqvist, L.; Kitchin, J. R.; Bligaard, T.; Jónsson, H. J. Phys. Chem. B 2004, 108, 17886-17892.

(8) Greeley, J.; Stephens, I. E. L.; Bondarenko, A. S.; Johansson, T. P.; Hansen, H. A.; Jaramillo, T. F.; Rossmeisl, J.; Chorkendorff, I.; Nørskov, J. K. Nature Chem. 2009, 1, 552-556.

(9) Miller, D.; Öberg, H.; Kaya, S.; Sanchez Casalongue, H.; Friebel, D.; Anniyev, T.; Ogasawara, H.; Bluhm, H.; Pettersson, L. G. M.; Nilsson, A. Phys. Rev. Lett. 2011, 107, 195502.

(10) Teliska, M.; Murthi, V. S.; Mukerjee, S.; Ramaker, D. E. J. Electrochem. Soc. 2005, 152, A2159-A2169.

(11) Vukmirovic, M. B.; Zhang, J.; Sasaki, K.; Nilekar, A. U.; Uribe, F.; Mavrikakis, M.; Adzic, R. R. Electrochim. Acta 2007, 52, 2257-2263.

(12) Zhang, J.; Mo, Y.; Vukmirovic, M. B.; Klie, R.; Sasaki, K.; Adzic, R. R. J. Phys. Chem. B 2004, 108, 10955-10964.

(13) Zhang, J.; Sasaki, K.; Sutter, E.; Adzic, R. R. Science 2007, $315,220-222$.

(14) Teliska, A.; O’Grady, W. E.; Ramaker, D. E. J. Phys. Chem. $B$ 2005, 109, 8076-8084.

(15) Mukerjee, S.; Srinivasan, S.; Soriaga, M. P.; Mcbreen, J. J. Electrochem. Soc. 1995, 142, 1409-1422.

(16) Mukerjee, S.; McBreen, J. J. Electroanal. Chem. 1998, 448, $163-171$.

(17) Tada, M.; Murata, S.; Asakoka, T.; Hiroshima, K.; Okumura, K.; Tanida, H.; Uruga, T.; Nakanishi, H.; Matsumoto, S.; Inada, Y.; Nomura, M.; Iwasawa, Y. Angew. Chem. Int. Ed. 2007, 46, 43104315.

(18) Imai, H.; Izumi, K.; Matsumoto, M.; Kubo, Y.; Kato, K.; Imai, Y. J. Am. Chem. Soc. 2009, 131, 6293-6300.

(19) Allen, P. G.; Conradson, S. D.; Wilson, M. S.; Gottesfeld, S.; Raistrick, I. D.; Valerio, J.; Lovato, M. J. Electroanal. Chem. 1995, 384, 99-103.

(20) Principi, E.; Witkowska, A.; Dsoke, S.; Marassi, R.; Cicco, A. D. Phys. Chem. Chem. Phys. 2009, 11, 9987-9995.

(21) Teliska, M.; O’Grady, W. E.; Ramaker, D. E. J. Phys. Chem. B 2004, 108, 2333-2344.

(22) Friebel, D.; Miller, D. J.; O’Grady, C. P.; Anniyev, T.; Bargar, J.; Bergmann, U.; Ogasawara, H.; Wikfeldt, K. T.; Pettersson, L. G. M.; Nilsson, A. Phys. Chem. Chem. Phys. 2011, 13, 262-266.

(23) Friebel, D.; Miller, D. J.; Nordlund, D.; Ogasawara, H.; Nilsson, A. Angew. Chem. Int. Ed. 2011, 50, 10190-10192, Angew. Chem. 2011, 123, 10372-10374.

(24) Zhang, J. L.; Vukmirovic, M. B.; Xu, Y.; Mavrikakis, M.; Adzic, R. R. Angew. Chem. Int. Ed. 2005, 44, 2132-2135.

(25) Duisberg, M.; Dräger, M.; Wandelt, K.; Gruber, E. L. D.; Schmid, M.; Varga, P. Surf. Sci. 1999, 433, 554-558.

(26) Wu, Z.-L.; Zang, Z.-H.; Yau, S.-L. Langmuir 2000, 16, 35223528 .

(27) Anjos, D. M.; Rigsby, M. A.; Wieckowski, A. J. Electroanal. Chem. 2010, 639, 8-14.

(28) Friebel, D.; Schlaup, C.; Broekmann, P.; Wandelt, K. Surf. Sci. 2006, 600, 2800-2809.

(29) Friebel, D.; Schlaup, C.; Broekmann, P.; Wandelt, K. Phys. Chem. Chem. Phys. 2007, 9, 2142-2145.

(30) Ocko, B. M.; Wang, J.; Davenport, A.; Isaacs, H. Phys. Rev. Lett. 1990, 65, 1466-1469. 95.

(32) Waychunas, G. A. In Rev. Mineral. Geochem.; Mineralogical Soc America, 2002; Vol. 49, pp. 267-315.

(33) Webb, S. M. Phys. Scr. 2005, T115, 1011-1014.

(34) Rehr, J. J.; Albers, R. C.; Zabinsky, S. I. Phys. Rev. Lett. 1992, 69, 3397-3400.

(35) Ankudinov, A. L.; Ravel, B.; Rehr, J. J.; Conradson, S. D. Phys. Rev. B 1998, 58, 7565-7576.

(36) Safonova, O. V.; Tromp, M.; Bokhoven, J. A. van; Groot, F. M. F. de; Evans, J.; Glatzel, P. J. Phys. Chem. B 2006, 110, 16162 16164.

(37) Glatzel, P.; Singh, J.; Kvashnina, K. O.; Bokhoven, J. A. van J. Am. Chem. Soc. 2010, 132, 2555-2557.

(38) Ankudinov, A. L.; Rehr, J. J.; Low, J.; Bare, S. R. Phys. Rev. Lett. 2001, 86, 1642-1645.

(39) Ankudinov, A. L.; Rehr, J. J.; Low, J. J.; Bare, S. R. J. Synchrotron Rad. 2001, 8, 578-580.

(40) Mortensen, J. J.; Hansen, L. B.; Jacobsen, K. W. Phys. Rev. B 2005, 71, 035109 .

(41) Enkovaara, J.; Rostgaard, C.; Mortensen, J. J.; Chen, J.; Dułak, M.; Ferrighi, L.; Gavnholt, J.; Glinsvad, C.; Haikola, V.; Hansen, H. A.; Kristoffersen, H. H.; Kuisma, M.; Larsen, A. H.; Lehtovaara, L.; Ljungberg, M.; Lopez-Acevedo, O.; Moses, P. G.; Ojanen, J.; Olsen, T.; Petzold, V.; Romero, N. A.; Stausholm-Møller, J.; Strange, M.; Tritsaris, G. A.; Vanin, M.; Walter, M.; Hammer, B.; Häkkinen, H.; Madsen, G. K. H.; Nieminen, R. M.; Nørskov, J. K.; Puska, M.; Rantala, T. T.; Schiøtz, J.; Thygesen, K. S.; Jacobsen, K. W. J. Phys. Condens. Matter 2010, 22, 253202. 66

(42) Bahn, S. R.; Jacobsen, K. W. Comput. Sci. Eng. 2002, 4, 56-

(43) Hammer, B.; Hansen, L. B.; Nørskov, J. K. Phys. Rev. B 1999, 59, 7413-7421.

(44) Larsen, A. H.; Vanin, M.; Mortensen, J. J.; Thygesen, K. S.; Jacobsen, K. W. Phys. Rev. B 2009, 80, 195112.

(45) Bauer, E.; van der Merwe, J. H. Phys. Rev. B 1986, 33, 36573671 .

(46) Hoster, H. E.; Alves, O. B.; Koper, M. T. M. ChemPhysChem 2010, 11, 1518-1524.

(47) Lima, F. H. B.; Zhang, J.; Shao, M. H.; Sasaki, K.; Vukmirovic, M. B.; Ticianelli, E. A.; Adzic, R. R. J. Phys. Chem. C 2007, 111, 404-410.

(48) Horsley, J. A. J. Chem. Phys. 1982, 76, 1451-1458.

(49) Mansour, A. N.; Cook, J. W.; Sayers, D. E. J. Phys. Chem. 1984, 88, 2330-2334.

(50) Hämäläinen, K.; Siddons, D. P.; Hastings, J. B.; Berman, L. E. Phys. Rev. Lett. 1991, 67, 2850-2853.

(51) Garcia-Araez, N.; Climent, V.; Herrero, E.; Feliu, J. M.; Lipkowski, J. Electrochim. Acta 2006, 51, 3787-3793.

(52) Rossmeisl, J.; Nørskov, J. K.; Taylor, C. D.; Janik, M. J.; Neurock, M. J. Phys. Chem. B 2011, 110, 21833-21839.

(53) Feibelman, P. J.; Esch, S.; Michely, T. Phys. Rev. Lett. 1996, $77,2257$.

(54) Abrams, B. L.; Vesborg, P. C. K.; Bonde, J. L.; Jaramillo, T. F.; Chorkendorff, I. J. Electrochem. Soc. 2009, 156, B273-B282.

(55) Stamenkovic, V.; Mun, B. S.; Mayrhofer, K. J. J.; Ross, P. N.; Markovic, N. M.; Rossmeisl, J.; Greeley, J.; Nørskov, J. K. Angew. Chem. Int. Ed. 2006, 45, 2897-2901. 
1

2

3

4

5

6

7

8

9

10

11

12

13

14

15

16

17

18

19

20

21

22

23

24

25

26

27

28

29

30

31

32

33

34

35

36

37

38

39

40

41

42

43

44

45

46

47

48

49

50

51

52

53

54

55

56

57

58

59

60

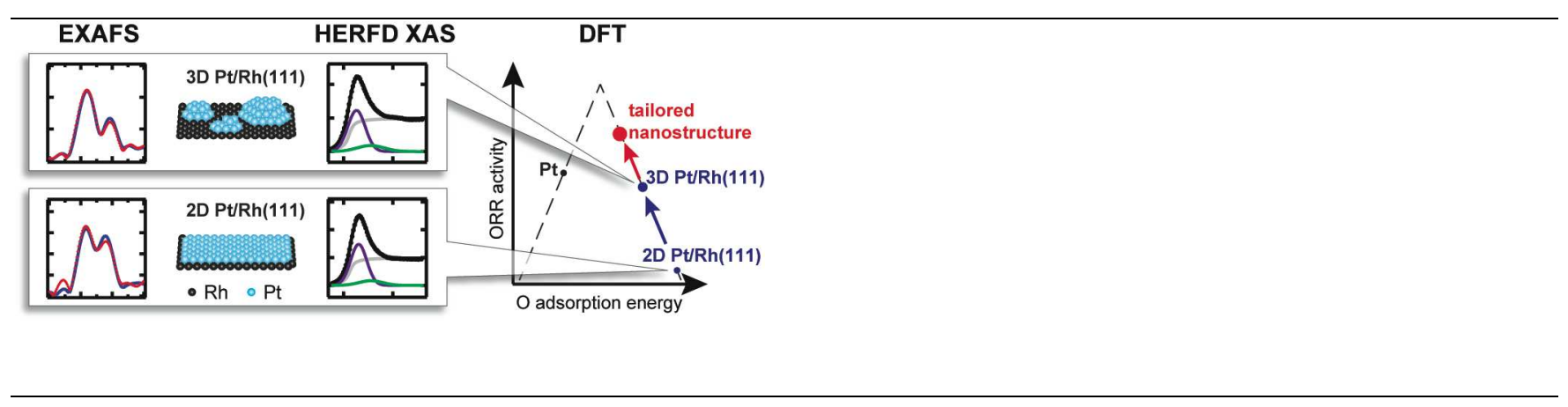



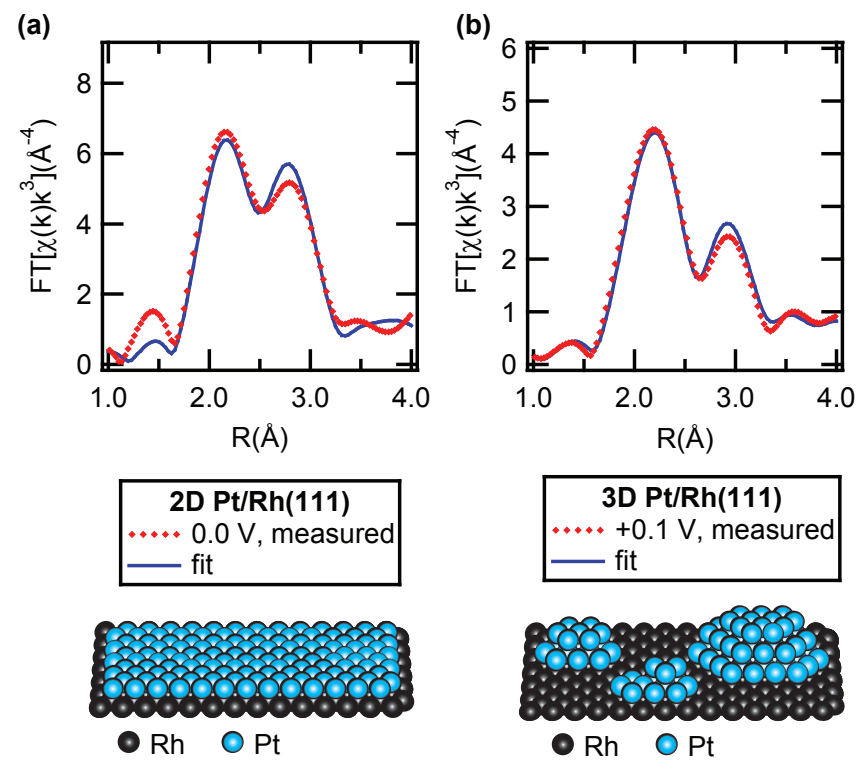

27

28

29

30

31

32

33

34

35

36

37

38

39

40

41

42

43

44

45

46

47

48

49

50

51

52

53

54

55

56

57

58

59

60 
1

2

3

4

5

6

7

8

9

10

11

12

13

14

15

16

17

18

19

20

21

22

23

24

25

26

27

28

29

30

31

32

33

34

35

36

37

38

39

40

41

42

43

44

45

46

47

48

49

50

51

52

53

54

55

56

57

58

59

60 (a)

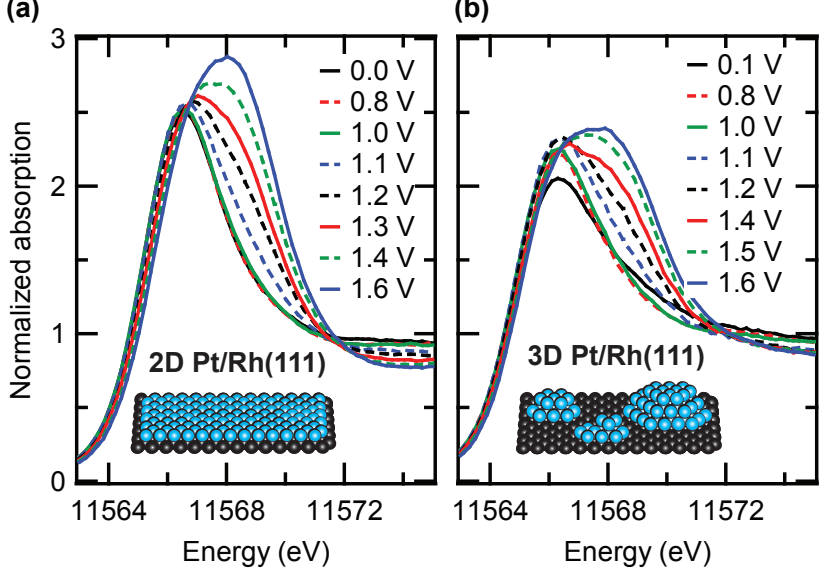




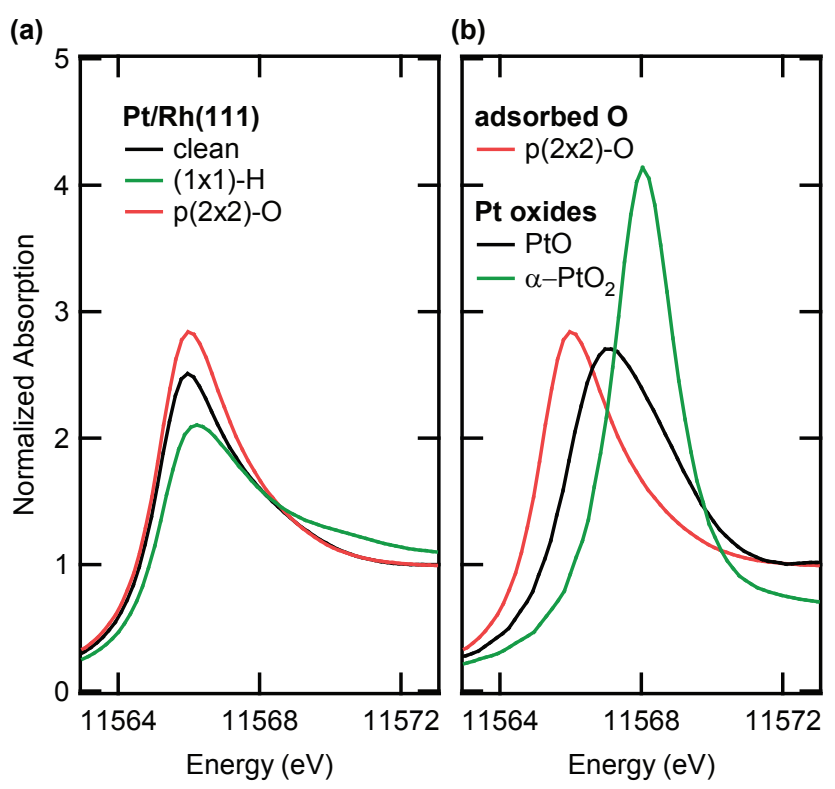


(a) $2 \mathrm{D} \mathrm{Pt} / \mathrm{Rh}$ (111)

1

2

3

4

5

6

7

8

9

10

11

12

13

14

15

16

17

18

19

20

21

22

23

24

25

26

27

28

29

30

31

32

33

34

35

36

37

38

39

40

41

42

43

44

45

46

47

48

49

50

51

52

53

54

55

56

57

58

59

60

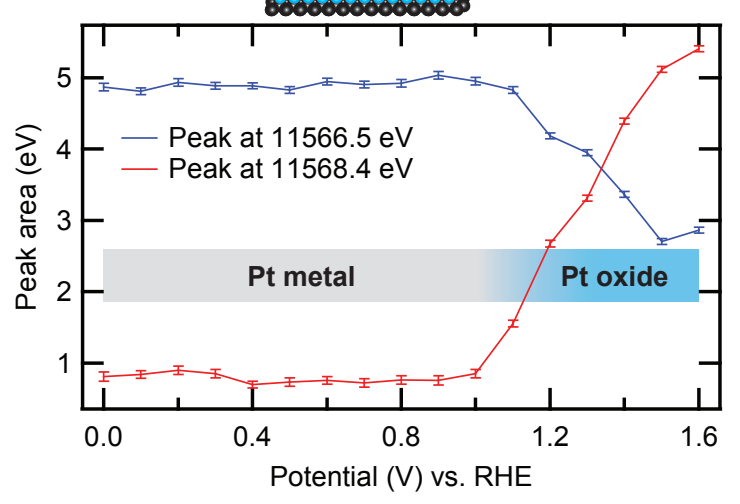

(b) $3 \mathrm{D} \mathrm{Pt} / \mathrm{Rh}(111)$

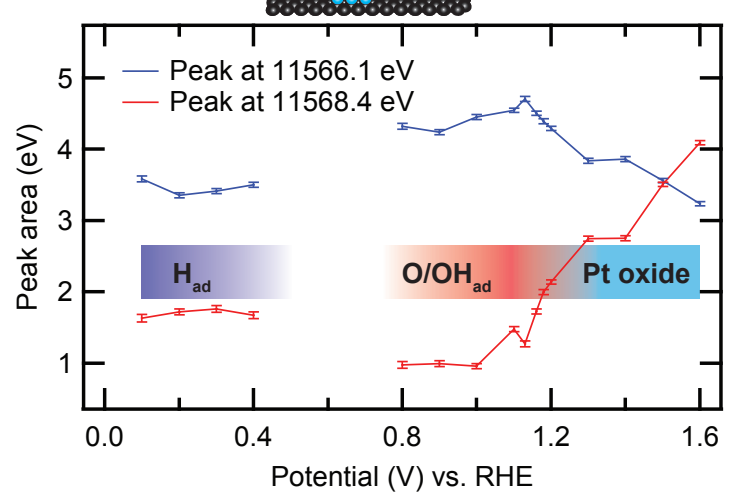

(c)

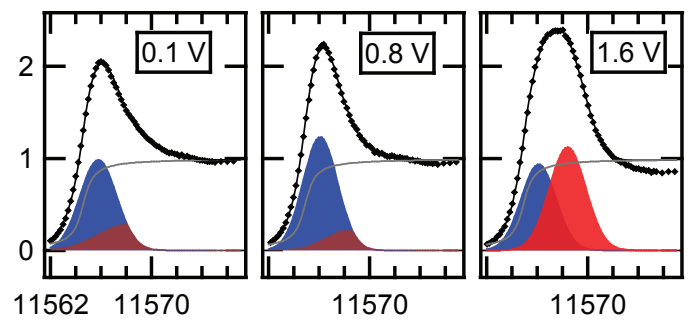




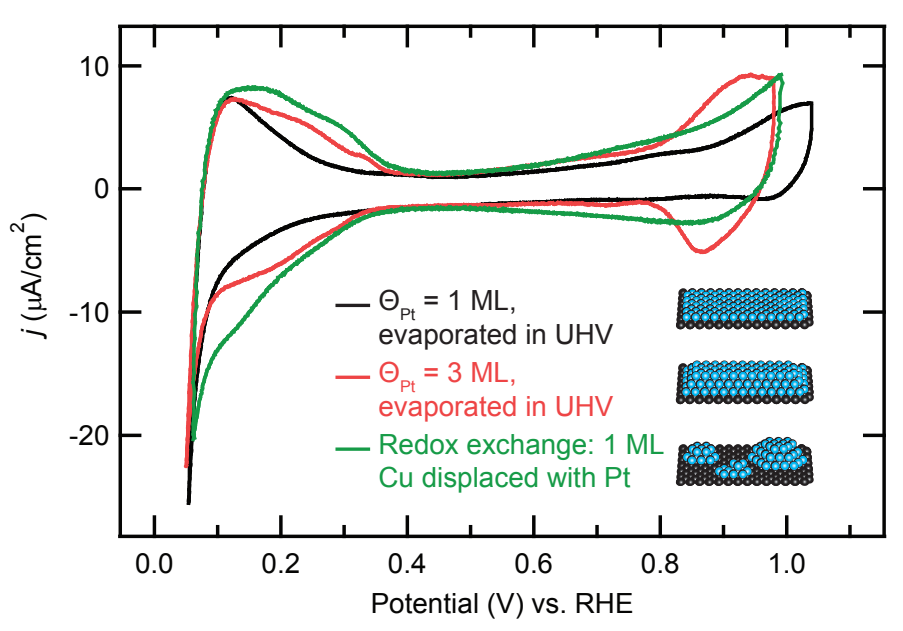

1

2

3

4

5

6

7

8

9

10

11

12

13

14

15

16

17

18

19

20

21

22

23

24

25

26

27

28

29

30

31

32

33

34

35

36

37

38

39

40

41

42

43

44

45

46

47

48

49

50

51

52

53

54

55

56

57

58

59

60 

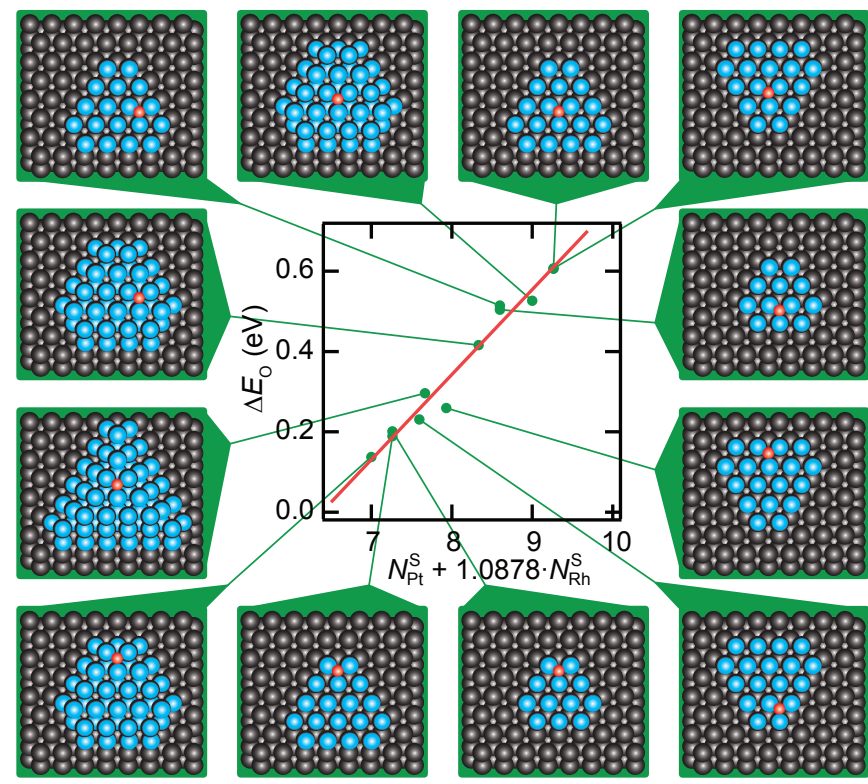

oRh oPt $\circ \mathrm{O}$

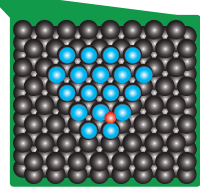


(a)

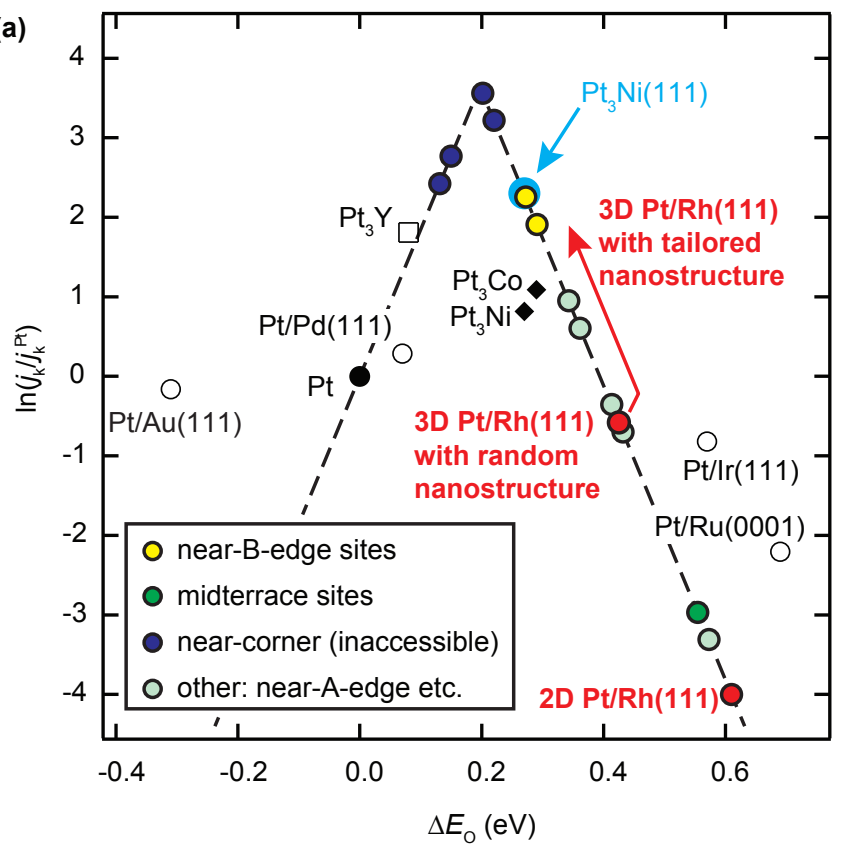

(b)

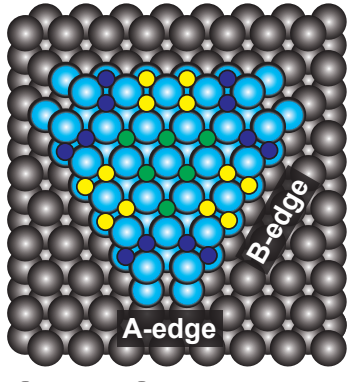

ORh OPt

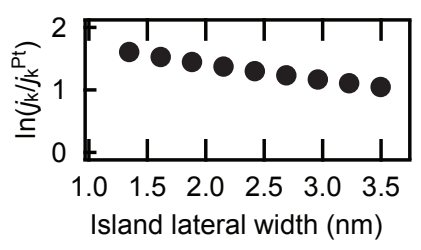

- inaccessible sites

o near-B-edge sites

- midterrace sites

32

33

34

35

36

37

38

39

40

41

42

43

44

45

46

47

48

49

50

51

52

53

54

55

56

57

58

59

60 


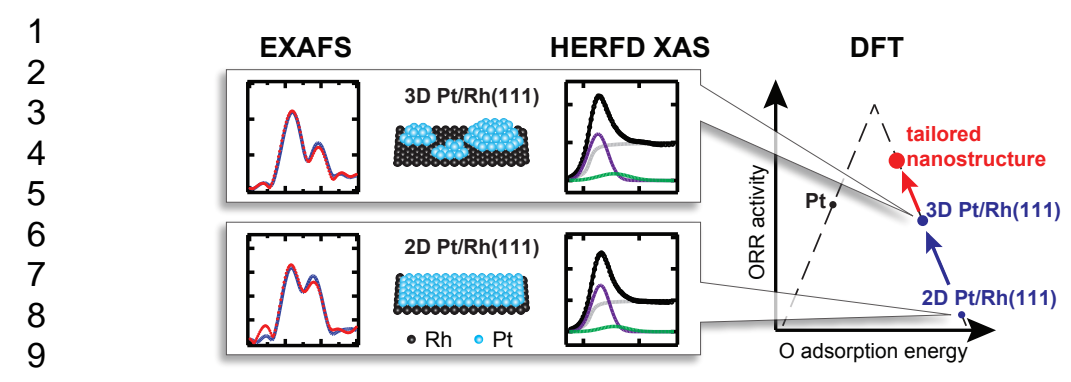

